\title{
Guidelines for Contributors to the JLTA Journal
}

1. Contributor must be a member of the association. This rule applies to co-authors as well.

2. All articles have to be written using a word processor or typewriter, written horizontally on A4 white paper. The original and one copy must be submitted. In addition, the digital file of the Word format should be sent to the JLTA Office, as an attachment.

3. On the top page, the title of the article, author's affiliation and name should be written. The page number must not be printed but indicated by pencil in the upper right hand corner.

4. When the article is written in Japanese, an English summary (about 300 words) has to be placed before the Japanese text. The English should be checked by a native speaker before submission.

5. Each sheet should have 3 centimeter margins at the top and the bottom and on both sides. Japanese manuscripts should have 40 characters to the line with 40 lines to the page. The article must be within 20 pages including the main text, notes, references, tables and charts. The notes should be put at the end of the text before the references. Tables and charts should be numbered serially.

6. The format of the references must follow American Psychological Association. 2001. Publication manual of the American Psychological Association. Fifth Edition.

7. The acceptance of the article will be decided after vetting. When the article is accepted and published, the member must pay a publishing fee $(5,000$ yen per article). Members have to indicate their address when they submit an article. The article will be reduced to B5 size and printed. The submitted article is not returned to the contributors.

8. The contributors who paid the publishing fee will get 20 copies of the off print of their paper for free. Those contributors needing much more off prints should inform the Secretariat of the number of copies (in multiples of 20 copies). The extra off prints are the expense of the contributor.

9. The deadline for submissions is April 30 every year.

10. Articles should be submitted to the Secretariat at the address below.

The Secretariat, Japan Language Testing Association

758 Wakamiya, Chikuma-shi, Nagano-ken, 389-0813, JAPAN

Phone: 026-275-1964 FAX: 026-275-1970

e-mail: youichi@avis.ne.jp

URL: http://www.avis.ne.jp/ youichi/JLTA.html 